\title{
Changes of N6-methyladenosine modulators promote breast cancer progression
}

\author{
Lianpin $\mathrm{Wu}^{1}$, Dengying $\mathrm{Wu}^{1}$, Jinfeng Ning ${ }^{2}$, Wei $\mathrm{Liu}^{3}$ and Donghong Zhang ${ }^{1,4^{*}}$
}

\begin{abstract}
Background: Breast cancer (BC) displays striking genetic, epigenetic and phenotypic diversity. $\mathrm{N}^{6}$-methyladenosine (m6A) in mRNA has emerged as a crucial epitranscriptomic modification that controls cancer self-renewal and cell fate. However, the key enzymes of m6A expression and function in human breast carcinogenesis remain unclear.

Methods: The expression of m6A methylases (METTL3, METTL14 and WTAP) and demethylases (FTO and ALKBH5) were analyzed by using ONCOMINE and The Cancer Genome Atlas databases and in 36 pairs of BC and adjacent non-cancerous tissue. The level of m6A in BC patients was detected by ELISA, and the function of m6A was analyzed by 3-(4,5-dimethylthiazol-2-yl)-2,5-diphenyltetrazolium bromide (MTT) assay, colony formation assay and transwell assay. The database of bc-GenExMiner v4.0, Kaplan-Meier Plotter and cBioPortal were queried for correlation, mutation and prognosis analysis of $\mathrm{BC}$.
\end{abstract}

Results: The m6A methylases and demethylases were dysregulated in several major malignant tumors. Specifically, the expression of all m6A methylases was reduced in BC as compared with normal controls, but the demethylase ALKBH5 was induced in ONCOMINE databases and confirmed in clinical patients. METTL14 expression was positively correlated with METTL3 expression, and both showed high expression in normal breast-like and luminal-A and -B BC. Functionally, reducing m6A expression by overexpressing METTL14 and/or knockdown of ALKBH5 could inhibit breast cell viability, colony formation and cell migration. Furthermore, Kaplan-Meier, meta-analysis and univariate Cox assay showed that the expression of m6A members including METTL3, METTL14, WTAP and FTO but not their gene mutation and amplification, was tightly associated with cancer progression and poor survival.

Conclusions: Changes of m6A modulators reduced m6A may promote tumorigenesis and predict poor prognosis in BC.

Keywords: N6-methyladenosine, Breast cancer, Prognosis, Migration; transcription

\section{Background}

One of the hallmarks of cancer is dysregulated gene expression. A new concept of the "epitranscriptome" was introduced as a result of transcriptome-wide mapping of $\mathrm{N}^{6}$-methyladenosine (m6A), involved in a diverse set of mRNA transcription, splicing, nuclear export, localization, translation, and stability functions [1].

\footnotetext{
*Correspondence: donghong1228@163.com

'Department of Cardiology, The Second Affiliated Hospital of Wenzhou Medical University, 109 Xueyuan Road, Wenzhou 325027, Zhejiang, China

${ }^{4}$ Center for Molecular and Translational Medicine, Georgia State University,

157 Decatur Street SE, Atlanta, GA 30303, USA

Full list of author information is available at the end of the article
}

Intense research and accumulating data on the m6A machinery has revealed the major enzymes involved in $\mathrm{m} 6 \mathrm{~A}$ modification.

The m6A methylation is dynamic, reversible and mediated by multiprotein "writers" (methylases) and "erasers" (demethylases). Writers are methyltransferase-like 3 (METTL3), METTL14 and Wilms tumor 1-associated protein (WTAP). METTL14, together with METTL3, forms a stable heterodimer of methyltransferase complex that mediates cellular m6A deposition on mammalian mRNAs. Knockdown of METTL3 or METTL14 substantially decreases m6A mRNA levels [2]. WTAP itself does

(c) The Author(s). 2019 Open Access This article is distributed under the terms of the Creative Commons Attribution 4.0 International License (http://creativecommons.org/licenses/by/4.0/), which permits unrestricted use, distribution, and 
not possess methylation activity because it lacks a conserved catalytic methylation domain, but it helps coordinate the localization of the METTL3-METTL14 heterodimer into nuclear speckles, thereby facilitating m6A deposition [3]. The m6A erasers include fat-mass- and obesity-associated protein (FTO) and its homolog AlkB family member 5 (ALKBH5); both selectively reverse m6A to adenosine in nuclear RNA [4]. Thus, identifying the character and regulation of the complex of mammalian m6A methylation machinery is the first step toward deciphering the selectivity and biological functions of m6A deposition in eukaryotic mRNAs.

Although m6A is the most prevalent internal modification that occurs in mRNA, its roles in biological processes have just begun to be uncovered. Previous studies implicated a role for m6A mRNA methylation during carcinogenesis [5], stem cell fate [6], spermatogenesis [4], circadian rhythms [7], and other diseases [8]. Therefore, questions are raised about reversible RNA methylation/demethylation in various malignant tumors. For m6A methylases, METTL3 has been reported to promote the growth and tumorigenesis of human liver cancer cells [9], acute myeloid leukaemia cells [5, 10] and glioblastoma stem cells [11] but also act as a tumor suppressor in renal cell carcinoma [12]. METTL14 expression could also increase the tumorigenesis of glioblastoma stem cells [11] but suppress the metastatic potential of hepatocellular carcinoma [13]. Similarly, WTAP acts as a novel oncogenic protein in acute myeloid leukemia [14], and its expression predicts poor prognosis in malignant glioma [15]. For m6A demethylases, previous studies have suggested that FTO has an oncogenic role in acute myeloid leukemia $[16,17]$. Overexpression of ALKBH5 could increase the frequency of the breast cancer (BC) stem-cell phenotype by m6A-mediated demethylation of NANOG gene [18].

However, the roles of distinct writers and erasers of $\mathrm{m} 6 \mathrm{~A}$ in the tumorigenesis and prognosis of $\mathrm{BC}$, the most common cause of death from cancer in women worldwide, are largely unknown. Accordingly, we explored the expression, association and prognostic effect of m6A enzymes in different clinicopathologic and molecular subtypes as well as the function of $\mathrm{m} 6 \mathrm{~A}$ in breast tumorigenesis by using data from various databases and verified in clinical patient specimens. We also performed gain- of-function and loss-of-function studies. These findings will be helpful for understanding the pathogenic molecular mechanisms of $\mathrm{m} 6 \mathrm{~A}$ and for diagnosis.

\section{Methods}

\section{Patients}

We collected samples of fresh $\mathrm{BC}$ cancerous tissues and paired normal tissues (at least $5 \mathrm{~cm}$ away from the margins) from 36 patients with $\mathrm{BC}$ (mean age $49.5 \pm 8.7$ years) in the Second Affiliated Hospital of Wenzhou Medical University from 2012 to 2015. Tissue histology was confirmed by two pathologists, and patients did not have ductal carcinoma in situ, atypical hyperplasia or benign breast disease. The clinicopathologic parameters of $\mathrm{BC}$ were determined according to the World Health Organization histological classification criteria [19].

\section{Cell culture, transfection and infection}

Human MDA-MB-231 cells (Catalog Number: SCSP-5043) were purchased from the Shanghai Institute for Biological Sciences, Chinese Academy of Sciences on the $2 / 14 / 2018$. MDA-MB-231 cell line was originally derived from pleural effusion of a 51-year-old Caucasian female patient with metastatic breast adenocarcinoma. The identity of the cell line were verified by Single Tandem Repeat (STR) profiling method performed by Eurofins Medigenomix (Ebersberg, Germany) and repeatedly tested in our laboratory for mycoplasma contamination, which could be excluded. We have also double checked the NCBI database for none of misidentification and contamination. The MDA-MB-231 cells were grown in DMEM (Gibco, 11,965) media supplemented with 10\% fetal bovine serum (FBS) and 1\% 100× Pen Strep (Gibco, $15,140)$ at $37^{\circ} \mathrm{C}$ in a humidified atmosphere containing $5 \% \mathrm{CO}_{2}$. After culture for $24 \mathrm{~h}$ at $70 \%$ density, cells were transfected with short-hairpin RNA (shRNA) for ALKBH5 knockdown (Santa Cruz Biotechnology, sc-93,856-SH) and/or pcDNA3/Flag-METTL14 plasmid (Addgene, \#53740) for METTL14 overexpression (OE-METTL14) by using Lipofectamine RNAiMAX Reagent or Lipofectamine 2000 Reagent (Thermo Fisher Scientific) following the manufacturer's protocols. shRNA-A control (Si-CN, Santa Cruz Biotechnology, sc-108,060) and control plasmid (OE-CN) of pcDNA3 Flag HA (Addgene, \#10792) were the transfection controls.

\section{Cell viability assay}

Cell viability was measured by Cell Counting Kit-8 (CCK8) assay. Overall, 5000 cells/well of MDA-MB-231 cells were seeded in 96-well plates. After transfection with shRNA or plasmid for $24 \mathrm{~h}$, cells were supplemented with $10 \mu \mathrm{l}$ CCK8 (Sigma, 96,992) and cultured for $2 \mathrm{~h}$ in a $5 \% \mathrm{CO}_{2}$ and $37^{\circ} \mathrm{C}$ incubator. Absorbance was measured at $450 \mathrm{~nm}$ wavelength. The effect on cell proliferation was assessed as the percent cell viability, with siRNA- and plasmid-control transfected cells considered $100 \%$ viable.

\section{Colony formation assays}

In total, 100 MDA-MB-231 cells transfected with shRNA and/or plasmid were seeded in 6-well ultra-low 
attachment plates (Corning). The growth medium was replaced every 3 days. Colonies were formed and imaged for colony size calculation at 6 days post-treatment. Colony diameter $>50 \mu \mathrm{m}$ was counted from three different wells.

\section{Cell transwell migration assay}

MDA-MB-231 cells transfected with shRNA and/or plasmid were incubated at $2 \times 10^{5}$ in transwell inserts with $0.8-\mu \mathrm{m}$ pore size (Corning, New York, USA) in 24-well plates for $24 \mathrm{~h}$. All cells were suspended in serum-free DMEM and seeded in triplicate in each insert. DMEM supplemented with 10\% FBS was used as a chemoattractant. Cells in the bottom inside of the membranes were removed. Migrating cells on the outside membrane were washed and stained with $0.1 \%$ crystal violet for $10 \mathrm{~min}$. The migrating cells were calculated by counting 5 randomly chosen fields under a microscope.

\section{ONCOMINE analysis}

The transcriptional levels of m6A enzymes in diverse cancer types and matched normal tissues were determined by analysis of the ONCOMINE database as described [20]. In brief, the analysis was performed online (https://www.oncomine.org) with use of Student $t$ test. $P<0.05$ was considered statistically significant, and the gene rank cutoff was the top $10 \%$.

\section{BC gene-expression miner v4.0 (BC-GenExMiner v4.0)}

bc-GenExMiner v4.0 contains 36 annotated genomic datasets for gene expression, prognostic and correlation. The expression of a target gene was compared by clinical criteria such as age, estrogen receptor status (ER) (by immunohistochemistry $[\mathrm{IHC}])$, progesterone receptor status (PR) (by IHC), HER2 receptor status (HER2) (by $\mathrm{IHC}$ ), and triple-negative $\mathrm{BC}$ and nodal status. Correlation maps and Pearson pairwise correlation plots among m6A family members were used for all patients. Prognostic results are presented by forest plots, univariate Cox analysis and Kaplan-Meier curves.

\section{Kaplan-Meier plotter}

The prognostic merits of candidate genes in human BC were evaluated by using bc-GenExMiner v4.0. The prognostic value was confirmed by using Kaplan-Meier Plotter (www.kmplot.com) [21], with hazard ratios (HRs) and $95 \%$ confidence intervals (CIs) and logrank $p$ value.

\section{cBioPortal}

The cBioPortal for Cancer Genomics provides both sequencing and pathological data for large-scale cancer genomics datasets [22]. The Molecular TAxonomy of BC International Consortium (METABRIC) [23, 24], a
BC dataset containing data for 2509 cases (the largest sample) with pathology reports, was selected for further analysis of m6A enzymes with cBioPortal (www.cbioportal.org) [25] and confirmed with The Cancer Genome Atlas (TCGA) database (1105 samples). Briefly, the genomic profiles included mutations, copy-number variance (CNV) from GISTIC, mRNA expression z-scores (RNA Seq V2 RSEM) and protein expression z-scores (RPPA). The Oncoprint in cBioPortal represents the proportion and distribution of samples with altered m6A enzyme expression. Overall survival for all $\mathrm{BC}$ patients was calculated according to the cBioPortal's online instructions.

\section{Quantitative RT-PCR (qRT-PCR)}

qRT-PCR of gene expression was conducted as we previously described [26, 27]. Briefly, total RNA was isolated and converted to cDNA with use of TRIzol reagent (Life Technologies) and the SuperScript III Reverse Transcriptase kit (Life Technologies). qRT-PCR amplification involved the Power SYBR Green PCR Master Mix (Life Technologies) and Applied Biosystems 7900HT Fast Real-Time PCR System (Invitrogen). Specific primers are in Additional file 1: Table S1. Amplification of $\beta$-ACTIN was an internal control. The relative expression of METTL3, METTL14, WTAP, FTO and ALKBH5 in BC tissue was normalized to corresponding normal control tissue. All qRT-PCR analyses were performed in biological triplicates for each sample.

\section{m6A quantification}

The change in global m6A total RNA level was measured by using the EpiQuik m6A RNA Methylation Quantification Kit (Colorimetric) (\#P-9005, Epigentek, Farmingdale, NY) according to the manufacturer's protocol. In total, $200 \mathrm{ng}$ total RNA extracted from clinical BC patients and transfected MDA-MB-231 cells was used for analysis.

\section{Statistical analysis}

All data are representative of at least three independent experiments and results are shown as mean \pm SD after the assessment of normality. SPSS 16.0 (SPSS Inc., Chicago, IL) was used for analysis. Student $t$ test was used to assess differences in mRNA expression of m6A members between $\mathrm{BC}$ and adjacent normal tissue as well as clinicopathological variables. One-way ANOVA followed by Tukey's test was used for analysis of differences among groups by transfection of shRNA or plasmid. Spearman correlation was used to analyze the correlation between m6A members [28]. $P<0.05$ was considered statistically significant. 


\section{Results}

Reduced m6A level and methylase expression in BC

ONCOMINE database analysis revealed that m6A enzymes were distinctively dysregulated in several major malignant tumors. Levels of the m6A methylase "writers," including METTL3, METTL14 and WTAP, were increased in brain, central nervous system (CNS), cervical, and head and neck cancer and sarcoma but decreased in BC, lymphoma and ovarian cancer as compared with normal controls. Conversely, levels of the m6A demethylase "erasers," including FTO and ALKBH5, were increased in kidney cancer and leukemia but decreased in $\mathrm{BC}$, brain, CNS and ovarian cancer (Fig. 1a).

Specifically, the expression of the m6A methylases METTL3, METTL14, and WTAP was reduced 1.575-, 1.200- and 1.883-fold in BC samples as compared with normal tissue, whereas that of the m6A demethylase ALKBH5 was 1.523-fold increased, as derived from TCGA data for BC (Fig. 1b). Consistently, most of these mRNA changes were confirmed by other studies, including Ma et al. [29], Richardon et al. [30], Turashvili et al. [31], Gluck et al. [32], Curtis et al. [24], and Finak et al. [33]. In addition, the above results were verified in our clinical BC patients: with 77.87, 80.19, 69.04 and $81.49 \%$ reduction of mRNA expression of METTL3, METTL14, WTAP and FTO and 1.71-fold induction of ALKBH5 mRNA expression in tumor tissue as compared with non-tumor tissue (Fig. 2a-e). Consistently, the decrease in expression of m6A methylases and increase in that of $\mathrm{m} 6 \mathrm{~A}$ demethylase contributed to reduced $\mathrm{m} 6 \mathrm{~A}$ level in $\mathrm{BC}$ tissue as compared with control tissue (Fig. 2f).

\section{Increase in m6A inhibited BC growth and metastasis}

METTL14 and ALKBH5 were reported as oncogene and tumor suppressor genes, respectively $[11,13,18,34]$. To investigate the functional roles of $\mathrm{m} 6 \mathrm{~A}$ in $\mathrm{BC}$, we established stable overexpression of METTL14 by transfection with pcDNA3/Flag-METTL14 plasmid and/or knockdown of ALKBH5 by transfection with shRNA in MDA-MB-231 cells (Fig. 3a, b). As expected,
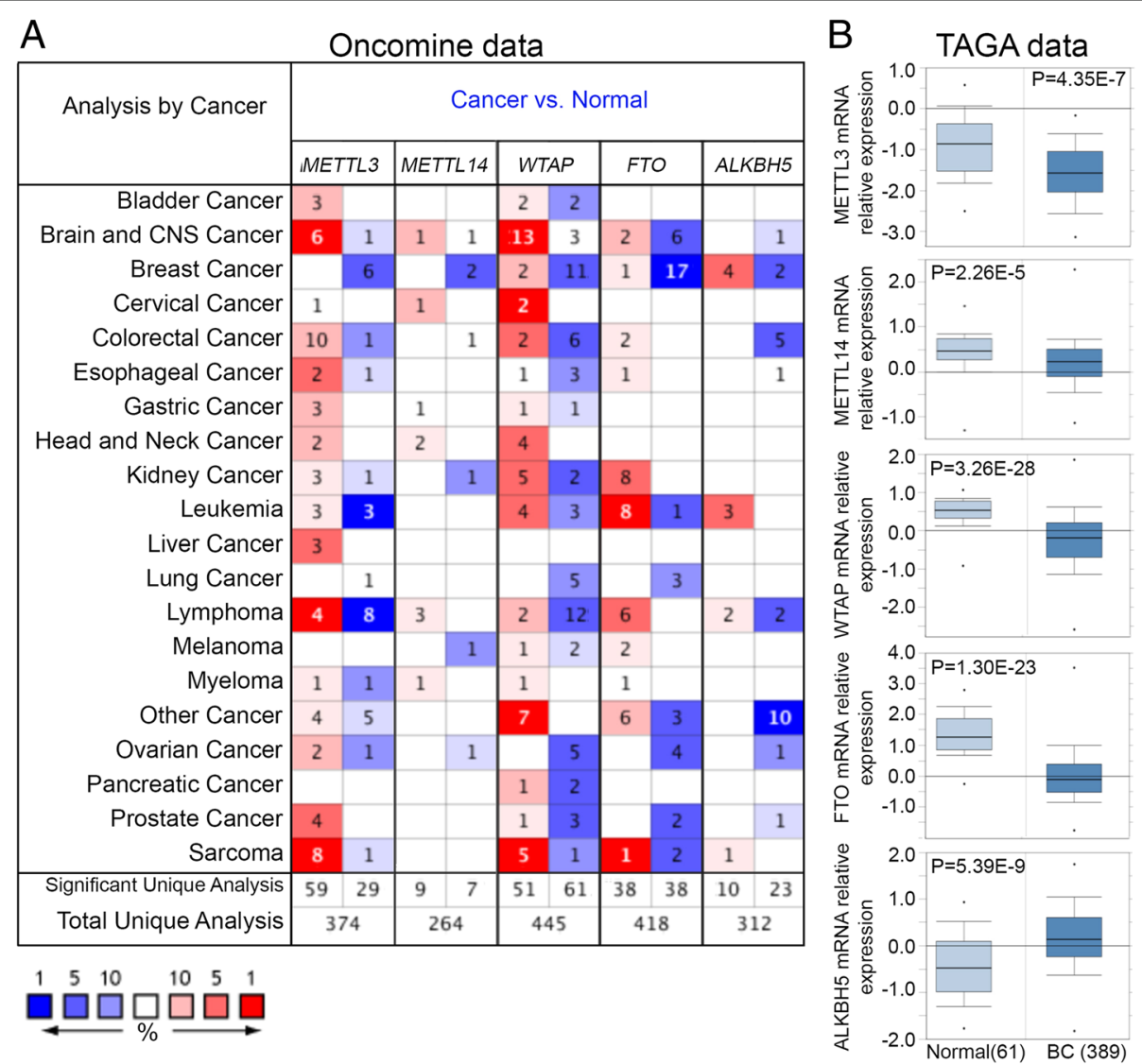

Fig. 1 Transcriptional pattern of m6A enzymes in major malignant tumors from ONCOMINE database analysis. a, The heat-map represents data with statistically significant upregulation (red) or downregulation (blue) of m6A factors in various human cancer tissues as compared with their normal control. The numbers in the heatmap indicate the published independent datasets of mRNA microarray experiments. b. Box plots from gene expression data in the The Cancer Genome Atlas (TCGA) database comparing the expression of specific m6A members, including methylases (METTL3, METTL14 and WTAP) and demetylases (FTO and ALKBH5) in normal and BC tissue 

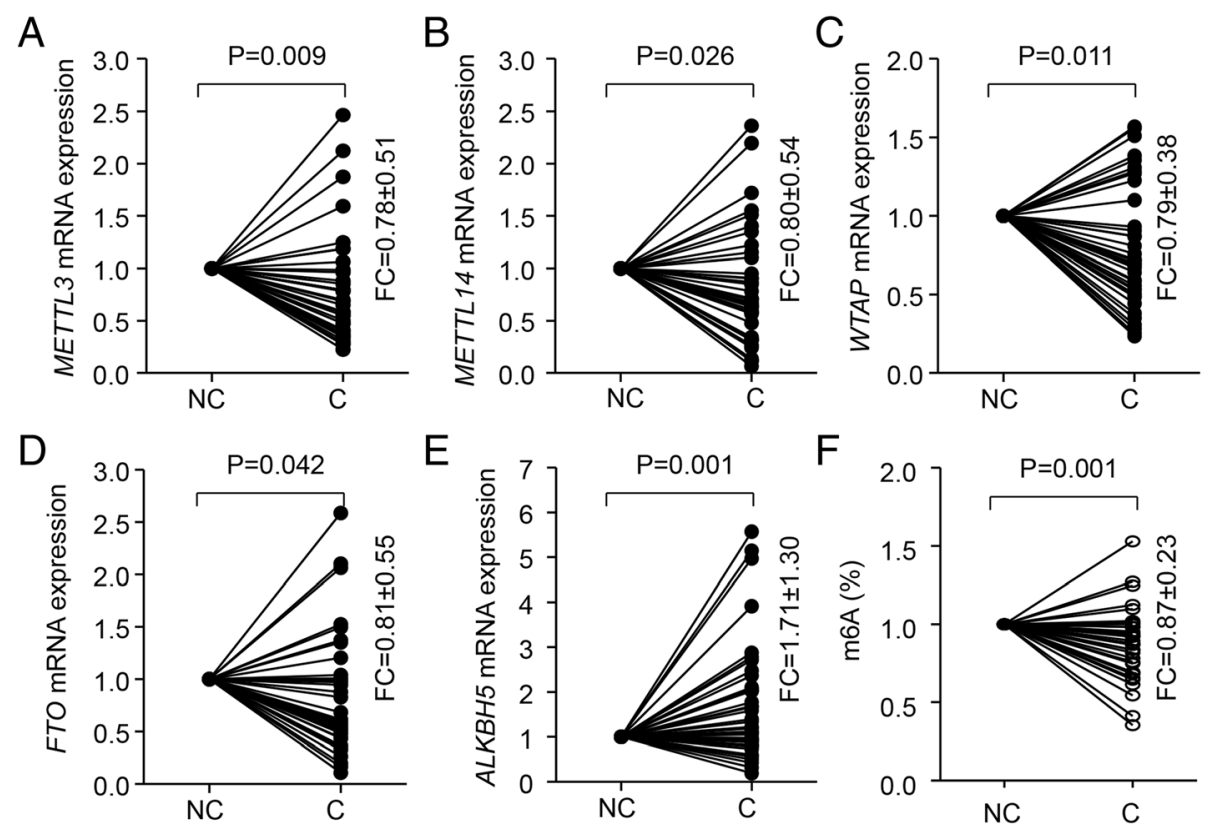

Fig. 2 mRNA expression of m6A members in BC patients. qRT-PCR analysis of mRNA expression of m6A members (a-e) and ELISA analysis globe m6A level (f) in breast cancer (c) and paired adjacent noncancerous (NC) tissue. FC, fold change

overexpression of METTL14 and/or knockdown of ALKBH5 remarkably induced m6A mRNA level (Fig. 3c). Importantly, m6A induction significantly suppressed BC cell viability (Fig. 3d) and inhibited MDA-MB-231 colony-formation abilities (Fig. 3e). Furthermore, m6A greatly suppressed cell migratory abilities (Fig. 3f, g). Thus, increased m6A RNA methylation could inhibit BC growth and metastasis.

\section{Relationship between m6A enzyme expression and molecular subtype as well as BC clinicopathology}

We next used bc-GenExMiner and compared the mRNA expression of m6A enzymes by molecular subtypes of BC. $\mathrm{ER}(+)$ or $\mathrm{PR}(+)$ status was associated with high mRNA levels of METTL3, METTL14, FOT and ALKBH5 but low level of WTAP as compared with negative status (Table 1). Triple-negative $\mathrm{BC}$ (TNBC) is a specific type of $\mathrm{BC}$, with $\mathrm{ER}(-)$ and $\mathrm{PR}(-)$ status and human epidermal growth factor receptor 2 (HER2)(-) status. We found the same mRNA expression trends in non-TNBC patients. As well, FTO mRNA expression was significantly downregulated in HER2(+) patients, with no significant difference in gene expression by age or nodal status. These observations were confirmed in our clinical patients (Table 2).

Furthermore, changes in $\mathrm{BC}$ patients differed by clinicopathologic parameters (Fig. 4a-e): both METTL3 and METTL14 were upregulated with normal breast-like and luminal- $\mathrm{A}$ and $-\mathrm{B} \mathrm{BC}$ as compared with basal-like and HER2-E types. mRNA level of FTO was high in normal breast-like and luminal-A BC. In contrast, the highest WTAP mRNA was found with basal-like, then normal breast-like BC. ALKBH5 expression did not change by clinicopathologic features.

\section{Correlation between m6A enzyme expression in $\mathrm{BC}$}

We first used bc-GenExMiner v4.0 correlation analysis to examine the relation between m6A mRNA enzyme expression in $\mathrm{BC}$ patients (Table 3). Among m6A methylases, METTL14 expression was positively correlated with METTL3 and WTAP expression. Also, among m6A demethylases, the mRNA expression of FTO and ALKBH5 was positively correlated. The expression of m6A methylases was negatively correlated with that of m6A demethylases, such as FTO and METTL3 and ALKBH5 but not METTL3 or FTO. These results were confirmed in our clinical study (Table 4),

\section{Reduced expression of m6A enzymes predicts poor prognosis in $\mathrm{BC}$}

Metastasis and biochemical relapse are important factors affecting the survival of $\mathrm{BC}$ patients. We next assessed the prognostic value of m6A enzyme levels in patients with BC. Reduced expression of METTL3, METTL14, WTAP and FTO but not ALKBH5 was associated with poor metastasis relapse (MR)-free survival in all $\mathrm{BC}$ patients by Kaplan-Meier analysis, meta-analysis (Additional file 1: Figure S1) and 

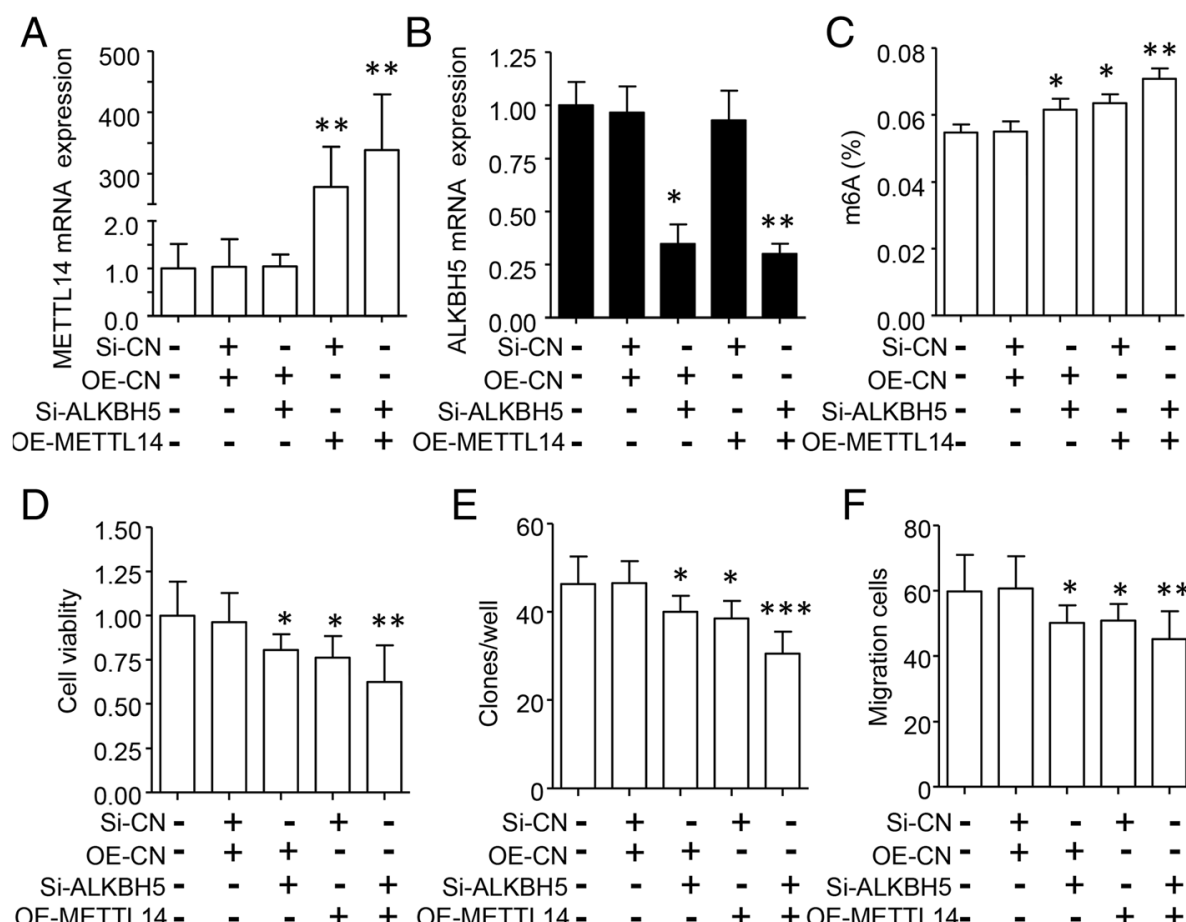

E
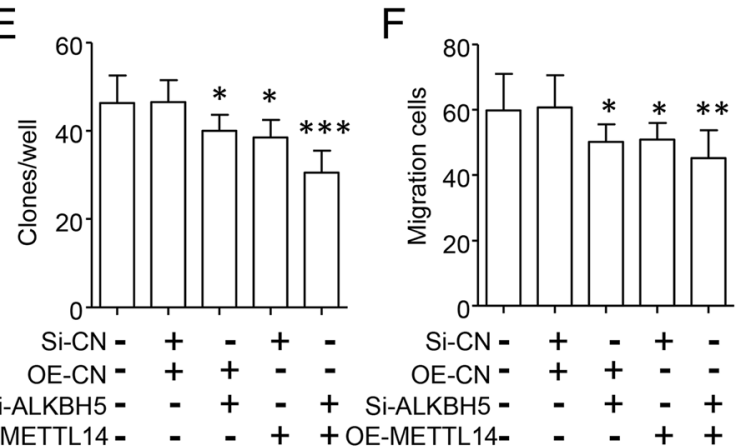

$G$
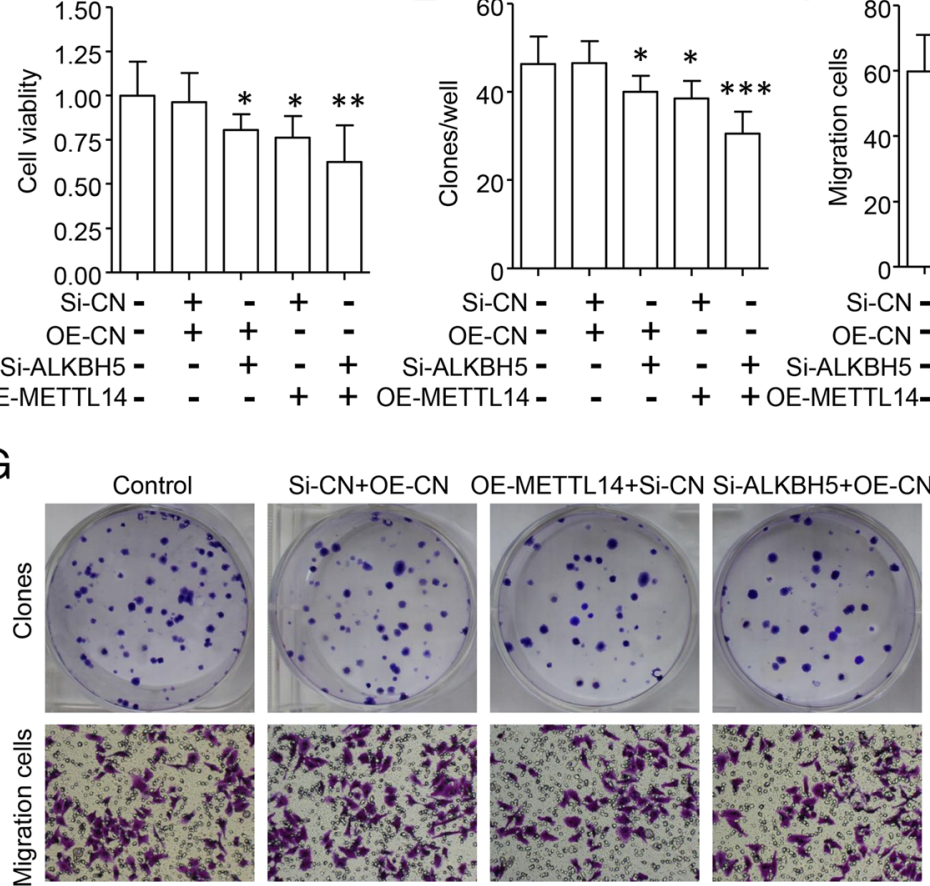

Si-ALKBH5+

OE-METTL14

Fig. 3 Induction of m6A inhibited BC growth and metastasis. (a, b) Stable Overexpression of METTL14 by pcDNA3/Flag-METTL14 and/or shRNA knockdown of ALKBH5 in MDA-MB-231 cells was verified by qRT-PCR assay. Overexpression of METTL14 and/or knockdown of METTL3 significantly induced global m6A level by ELISA assay (c) but reduced cell viability by CKK8 assay (d), colony formation ability (e) and cell migration by transwell assay $(\mathbf{f})$. (g) Representative images of colony formation and cell migration cells. ${ }^{*} P<0.05,{ }^{* *} P<0.01,{ }^{* * *} P<0.001$

univariate Cox analysis (Additional file 1: Table S2-S6) based on the bc-GenExMiner v4.0 database (Fig. 5). Similar prognostic observations were confirmed by using Kaplan-Meier Plotter (Additional file 1: Figure S2).

Univariate analysis indicated both nodal-negative and $\mathrm{ER}(+)$ and MR-free survival associated with elevated expression of METTL14 (HR $=0.72, P=0.0014)$, WTAP (HR $=0.77, P=0.0001)$ or FTO $(\mathrm{HR}=0.74, P<0.0001)$. A similar pattern was found for METTL3 expression with nodal (-) and ER (-) status and MR-free survival (HR $=0.82, P=0.0246)$. However, ALKBH5 could not predict prognosis for any types of $\mathrm{BC}$ (Additional file 1: Tables S7-S11).

\section{Genetically altered m6A enzymes affect overall but not} disease-free survival in $B C$

By using cBioPortal assay (METABRIC [23, 24]), we found genetic alterations, including amplification and deletion of m6A enzymes in 493 (24\%) samples of 2051 patients with breast-invasive carcinoma (Fig. 6a). However, overall survival did not differ with alterations in all m6A members (METT3, METTL14, WTAP, FTO and ALKBH5), which might be related to the few alterations (<6\% overall) (Fig. 6b-e).

\section{Discussion}

$\mathrm{BC}$ is the most common and second leading cause of cancer-related deaths among women worldwide [35]. 
Table 1 The relationship between m6A enzyme mRNA expression and clinicopathological parameters with breast cancer. (Data from bc-GenExMiner v4.0)

\begin{tabular}{|c|c|c|c|c|c|c|c|c|c|c|c|c|c|}
\hline \multirow[t]{2}{*}{ Parameter } & \multirow[t]{2}{*}{ Status } & \multicolumn{2}{|c|}{ METTL3 } & \multicolumn{2}{|c|}{ METTL14 } & \multicolumn{2}{|c|}{ WTAP } & \multicolumn{2}{|c|}{ KIAA1429 } & \multicolumn{2}{|l|}{ FTO } & \multicolumn{2}{|c|}{ ALKBH5 } \\
\hline & & No. & mRNA & No. & mRNA & No. & mRNA & No. & mRNA & No. & mRNA & No. & mRNA \\
\hline \multirow[t]{2}{*}{ Age } & $\leq 51$ & 1302 & 1 & 810 & 1 & 1303 & 1 & 548 & 1 & 1192 & 1 & 766 & 1 \\
\hline & $>51$ & 2051 & $\mathrm{Nc}$ & 1673 & Nc & 2051 & $\mathrm{Nc}$ & 959 & Nc & 1896 & $\mathrm{Nc}$ & 1546 & $U p^{* *}$ \\
\hline \multirow[t]{2}{*}{$\mathrm{ER}(\mathrm{IHC})$} & - & 1488 & 1 & 949 & 1 & 1376 & 1 & 453 & 1 & 1383 & 1 & 892 & 1 \\
\hline & + & 3810 & $U p^{* * *}$ & 2374 & $U p^{* * *}$ & 3588 & Down*** & 1282 & $U p^{* * *}$ & 3650 & $U p^{* * *}$ & 2261 & $U p^{* *}$ \\
\hline \multirow[t]{2}{*}{ PR $(I H C)$} & - & 871 & 1 & 560 & 1 & 729 & 1 & 270 & 1 & 871 & 1 & 560 & 1 \\
\hline & + & 1365 & $U p^{* * *}$ & 935 & $U p^{* * *}$ & 1175 & Down*** & 504 & $U p^{* * *}$ & 1365 & $U p^{* * *}$ & 935 & Up* \\
\hline \multirow[t]{2}{*}{ HER2 (IHC) } & - & 1286 & 1 & 548 & 1 & 1286 & 1 & 405 & 1 & 1286 & 1 & 548 & 1 \\
\hline & + & 175 & $\mathrm{Nc}$ & 134 & Nc & 175 & $\mathrm{Nc}$ & 122 & Down* & 175 & Down ${ }^{* *}$ & 134 & $\mathrm{Nc}$ \\
\hline \multirow[t]{2}{*}{ TNBC } & + & 356 & 1 & 179 & 1 & 356 & 1 & 116 & 1 & 356 & 1 & 179 & 1 \\
\hline & - & 3968 & $U p^{* * *}$ & 2494 & $U p^{* * *}$ & 3726 & Down*** & 1366 & $U p^{* *}$ & 3808 & Up* & 2381 & $\mathrm{Nc}$ \\
\hline \multirow[t]{2}{*}{ Nodal } & - & 2375 & 1 & 1251 & 1 & 2376 & 1 & 698 & 1 & 2230 & 1 & 1251 & 1 \\
\hline & + & 1432 & $\mathrm{Nc}$ & 1064 & $U p^{*}$ & 1432 & $\mathrm{Nc}$ & 571 & Nc & 1312 & $\mathrm{Nc}$ & 1064 & $\mathrm{Nc}$ \\
\hline
\end{tabular}

Nc No, change; Up upregulation, Down downregualtion, ER estrogen receptor, $P R$ progesterone-receptor, HER2 human epidermal growth factor receptor $2, T N B C$ triple-negative breast cancer. ${ }^{*} \mathrm{p}<0.05,{ }^{* *} \mathrm{p}<0.01,{ }^{* * *} \mathrm{p}<0.001$

Because of heterogeneity, the disease exhibits unique somatic mutations and gene dysregulation. Therefore, predicting and monitoring response to treatment and disease progression must be examined longitudinally with next-generation sequencing and array-based technologies, as well as bioinformatics. Recently, the molecule m6A has gained the attention of RNA biologists because it was functionally implicated in various biological processing, including carcinogenesis [36]. Thus, exploring the functional roles and underlying molecular mechanisms of $\mathrm{m} 6 \mathrm{~A}$ is necessary in $\mathrm{BC}$.

Here, we first determined that the expression of $\mathrm{m} 6 \mathrm{~A}$ methylases (METTL3, METTL14 and WTAP) was significantly decreased and that of a demethylase (FTO) was increased in $\mathrm{BC}$ tissue relative to normal tissue.
These patterns were closely correlated with levels of characteristic molecular markers and predicted poor survival in BC. m6A enzymes might serve as novel diagnostic and prognostic indicators of BC. Furthermore, we functionally demonstrated the essential role of $\mathrm{m} 6 \mathrm{~A}$ in inhibiting $\mathrm{BC}$ growth and migration. Therefore, our findings add a new layer of epigenetic alteration that contributes to the progression of $\mathrm{BC}$.

Identifying the expression pattern of m6A methylases and demethylases, which regulate the RNA methylation landscape in the individual cancer patient, is essential for understanding their molecular mechanism, diagnosis and treatment. Similar to previous observations in embryonic stem cells [6], by using multiple online transcriptome data available for various cancers, we found

Table 2 The relationship between m6A enzyme mRNA expression and clinicopathological parameters with clinical patients of breast

\begin{tabular}{|c|c|c|c|c|c|c|c|}
\hline Parameter & Status (No.) & METTL3 (mRNA) & $\begin{array}{l}\text { METTL14 } \\
\text { (mRNA) }\end{array}$ & $\begin{array}{l}\text { WTAP } \\
\text { (mRNA) }\end{array}$ & $\begin{array}{l}\text { KIAA1429 } \\
\text { (mRNA) }\end{array}$ & $\begin{array}{l}\text { FTO } \\
\text { (mRNA) }\end{array}$ & $\begin{array}{l}\text { ALKBH5 } \\
\text { (mRNA) }\end{array}$ \\
\hline \multirow[t]{2}{*}{$\overline{\text { Age }}$} & $\leq 51(16)$ & $0.89 \pm 0.54$ & $0.80 \pm 0.53$ & $0.80 \pm 0.44$ & $2.14 \pm 1.31$ & $0.92 \pm 1.71$ & $1.59 \pm 1.23$ \\
\hline & $>51(20)$ & $0.72 \pm 0.50$ & $0.81 \pm 0.56$ & $0.79 \pm 0.36$ & $1.85 \pm 1.24$ & $0.76 \pm 0.46$ & $1.78 \pm 1.38$ \\
\hline \multirow[t]{2}{*}{ ER (IHC) } & - (13) & $0.55 \pm 0.18$ & $0.53 \pm 0.30$ & $0.81 \pm 0.41$ & $1.44 \pm 1.39$ & $0.59 \pm 0.63$ & $1.07 \pm 0.50$ \\
\hline & $+(23)$ & $0.89 \pm 0.59^{*}$ & $0.93 \pm 0.59^{*}$ & $0.78 \pm 0.38$ & $2.21 \pm 1.12$ & $0.92 \pm 0.49^{*}$ & $2.02 \pm 1.48^{*}$ \\
\hline \multirow[t]{2}{*}{ PR (IHC) } & $-(15)$ & $0.59 \pm 0.23$ & $0.65 \pm 0.36$ & $0.78 \pm 0.44$ & $1.33 \pm 0.90$ & $0.63 \pm 0.46$ & $1.08 \pm 0.23$ \\
\hline & $+(21)$ & $0.95 \pm 0.63^{*}$ & $0.96 \pm 0.64^{*}$ & $0.81 \pm 0.35$ & $2.33 \pm 1.07^{*}$ & $1.01 \pm 0.58^{*}$ & $2.20 \pm 1.52^{*}$ \\
\hline \multirow[t]{2}{*}{ HER2 (IHC) } & $-(14)$ & $0.72 \pm 0.38$ & $0.81 \pm 0.45$ & $0.77 \pm 0.36$ & $2.46 \pm 1.32$ & $0.74 \pm 0.41$ & $1.48 \pm 0.71$ \\
\hline & $+(22)$ & $0.81 \pm 0.58$ & $0.81 \pm 0.59$ & $0.80 \pm 0.40$ & $1.67 \pm 1.11$ & $0.86 \pm 0.62$ & $1.83 \pm 1.55$ \\
\hline \multirow[t]{2}{*}{ TNBC } & $+(4)$ & $0.31 \pm 0.07$ & $0.30 \pm 0.21$ & $0.60 \pm 0.09$ & $0.89 \pm 0.36$ & $0.41 \pm 0.33$ & $1.13 \pm 0.68$ \\
\hline & $-(32)$ & $0.83 \pm 0.51^{*}$ & $0.96 \pm 0.54$ & $0.81 \pm 0.40$ & $2.08 \pm 1.26$ & $0.86 \pm 0.56$ & $1.77 \pm 1.36$ \\
\hline
\end{tabular}

$E R$ estrogen receptor, $P R$ progesterone-receptor, $H E R 2$ human epidermal growth factor receptor $2, T N B C$ triple-negative breast cancer. ${ }^{*} \mathrm{p}<0.05$ 

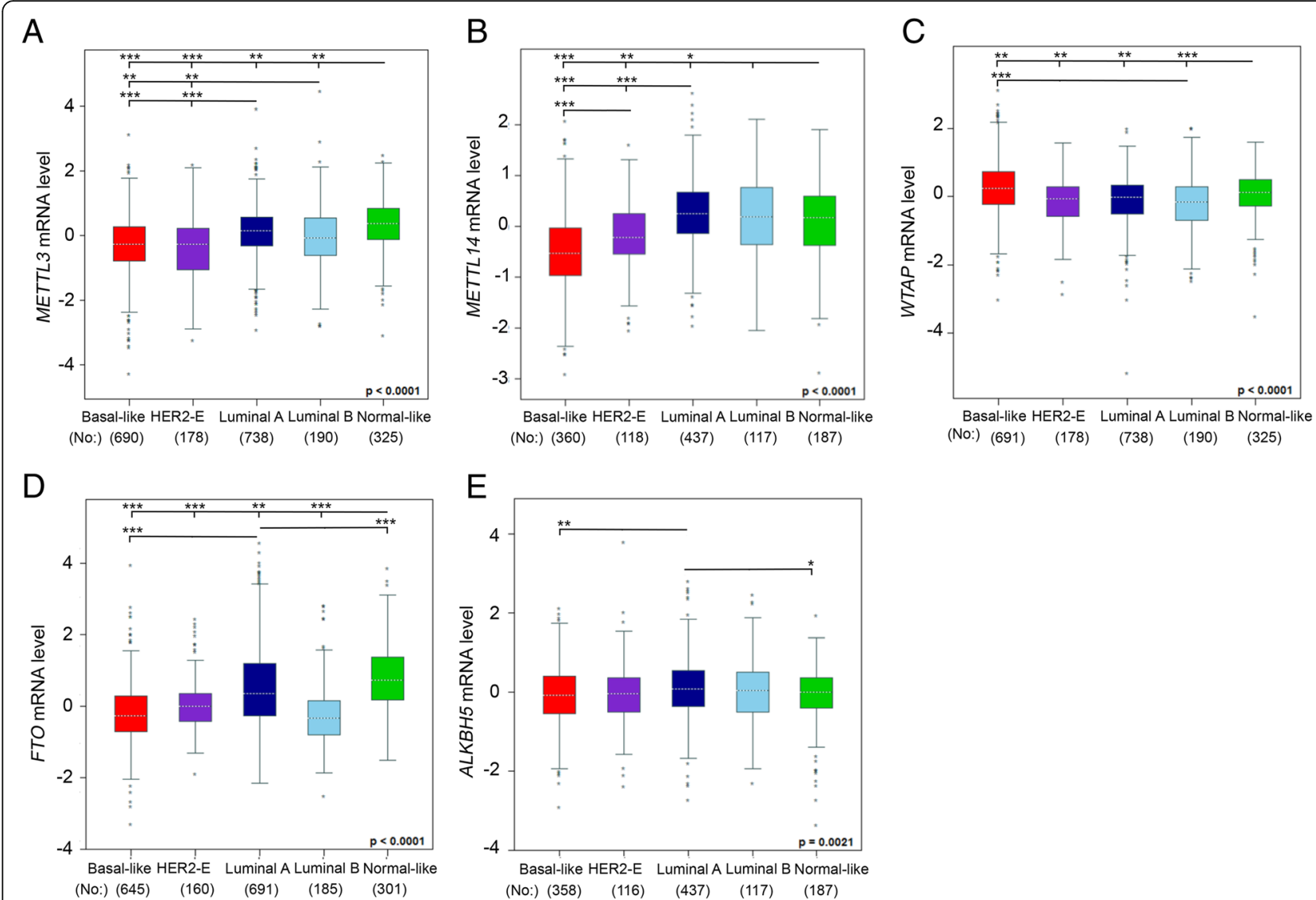

Fig. 4 Use of bc-GenExMiner 4.0 database to compare the mRNA expression of m6A enzymes in BC patients by clinicopathologic parameters. (ae) Global significant difference between groups was assessed by Welch's test, followed by Dunnett-Tukey-Kramer test for pairwise comparison. * $P<0.05 ;{ }^{* *} P<0.01 ;{ }^{* *} P<0.001$

that the contradicting functions of m6A members might be required for specific cancer development. For instance, the increased expression of METTL3 and METTL14 in brain and CNS cancer might explain their promotion role in growth and tumorigenesis of glioblastoma stem cells [11]. These results indicate that upregulation of METTL3 and METTL14 is required for the development of glioblastoma. Similarly, upregulation of
FTO is necessary for its oncogenic role in acute myeloid leukemia [16]. Previous studies indicated that ALKBH5 maintains tumorigenicity and proliferation of $\mathrm{BC}$ stem cells and glioblastoma stem-like cells [18, 34, 37]. In at least three database searches, including the largest population (593 samples) in the TCGA data, we found a consistent decrease in expression of m6A enzymes during $\mathrm{BC}$ development. However, we could not implicate the

Table 3 Pairwise correlation analysis of m6A enzyme levels for all BC patients. (Data from bc-GenExMiner v4.0)

\begin{tabular}{|c|c|c|c|c|c|}
\hline Gene correlation & METTL3 & METTL14 & WTAP & KIAA1429 & FTO \\
\hline METTL14 & $\begin{array}{l}r=0.22^{* * *} \\
(N=3374)\end{array}$ & 1 & - & - & - \\
\hline WTAP & $\begin{array}{l}r=-0.03 \\
(N=5014)\end{array}$ & $\begin{array}{l}r=0.05^{* *} \\
(N=3029)\end{array}$ & 1 & - & - \\
\hline KIAA1429 & $\begin{array}{l}r=0.02 \\
(N=1758)\end{array}$ & $\begin{array}{l}r=0.19^{* * *} \\
(N=1758)\end{array}$ & $\begin{array}{l}r=0.04 \\
(N=1758)\end{array}$ & 1 & - \\
\hline FTO & $\begin{array}{l}r=0.03^{*} \\
(N=5095)\end{array}$ & $\begin{array}{l}r=0.07^{* * *} \\
(N=3109)\end{array}$ & $\begin{array}{l}r=0.02 \\
(N=4749)\end{array}$ & $\begin{array}{l}r=-0.08^{* *} \\
(N=1758)\end{array}$ & 1 \\
\hline ALKBH5 & $\begin{array}{l}r=-0.05^{* *} \\
(N=3203)\end{array}$ & $\begin{array}{l}r=0.15 \\
(N=3204)\end{array}$ & $\begin{array}{l}r=0.02 \\
(N=2858)\end{array}$ & $\begin{array}{l}r=0.02 \\
(N=1758)\end{array}$ & $\begin{array}{l}r=0.04^{*} \\
(N=2938)\end{array}$ \\
\hline
\end{tabular}

${ }^{*} \mathrm{P}<0.05 ;{ }^{* * \mathrm{P}}<0.01 ;{ }^{* * * \mathrm{P}}<0.0001$ as determined by Pearson correlation 
Table 4 Pairwise correlation analysis of m6A enzyme levels for clinical BC patients

\begin{tabular}{|c|c|c|c|c|c|}
\hline Gene correlation & METTL3 & METTL14 & WTAP & KIAA1429 & FTO \\
\hline METTL14 & $\begin{array}{l}r=0.312 \\
(P=0.031)\end{array}$ & 1 & - & - & - \\
\hline WTAP & $\begin{array}{l}r=0.185 \\
(P=0.101)\end{array}$ & $\begin{array}{l}r=0.24 \\
(0.084)\end{array}$ & 1 & - & - \\
\hline KIAA1429 & $\begin{array}{l}r=0.104 \\
(P=0.441)\end{array}$ & $\begin{array}{l}r=0.111 \\
(P=0.317)\end{array}$ & $\begin{array}{l}r=0.087 \\
(P=0.618)\end{array}$ & 1 & - \\
\hline FTO & $\begin{array}{l}r=0.41 \\
(P=0.014)\end{array}$ & $\begin{array}{l}r=0.134 \\
(P=0.262)\end{array}$ & $\begin{array}{l}r=0.041 \\
(P=0.870)\end{array}$ & $\begin{array}{l}r=-0.11 \\
(P=0.325)\end{array}$ & 1 \\
\hline ALKBH5 & $\begin{array}{l}r=-0.355 \\
(P=0.027)\end{array}$ & $\begin{array}{l}r=-0.371 \\
(P=0.020)\end{array}$ & $\begin{array}{l}r=0.14 \\
(P=0.249)\end{array}$ & $\begin{array}{l}r=0.08 \\
(P=0.645)\end{array}$ & $\begin{array}{l}r=0.301^{*} \\
(P=0.047)\end{array}$ \\
\hline
\end{tabular}

oncogenic role of METTL3 in BC because the expression of METTLE3 was consistently attenuated in findings from the TCGA and Gluck databases and in several studies [13, 23, 24, 30, 31]. Consistent with a recent study [38], decreased METTL3 expression combined with increased ALKBH5 expression contributed to significantly decreased m6A level in genetically defined immortalized and oncogenically transformed human mammary epithelial cells. Functionally, METTL14 was reported as a tumor suppressor for glioblastoma [11] and hepatocellular carcinoma [13] and ALKBH5 as oncogene for glioblastoma [34] and BC [18]. Therefore, overexpression of METTL14 and/or knockdown of ALKBH5 in MDA-MB-231 cells alone or together could reduce $\mathrm{m} 6 \mathrm{~A}$ level and further inhibit $\mathrm{BC}$ growth and migration.

However, findings for m6A and the role of m6A members in carcinogenesis can seem controversial. For

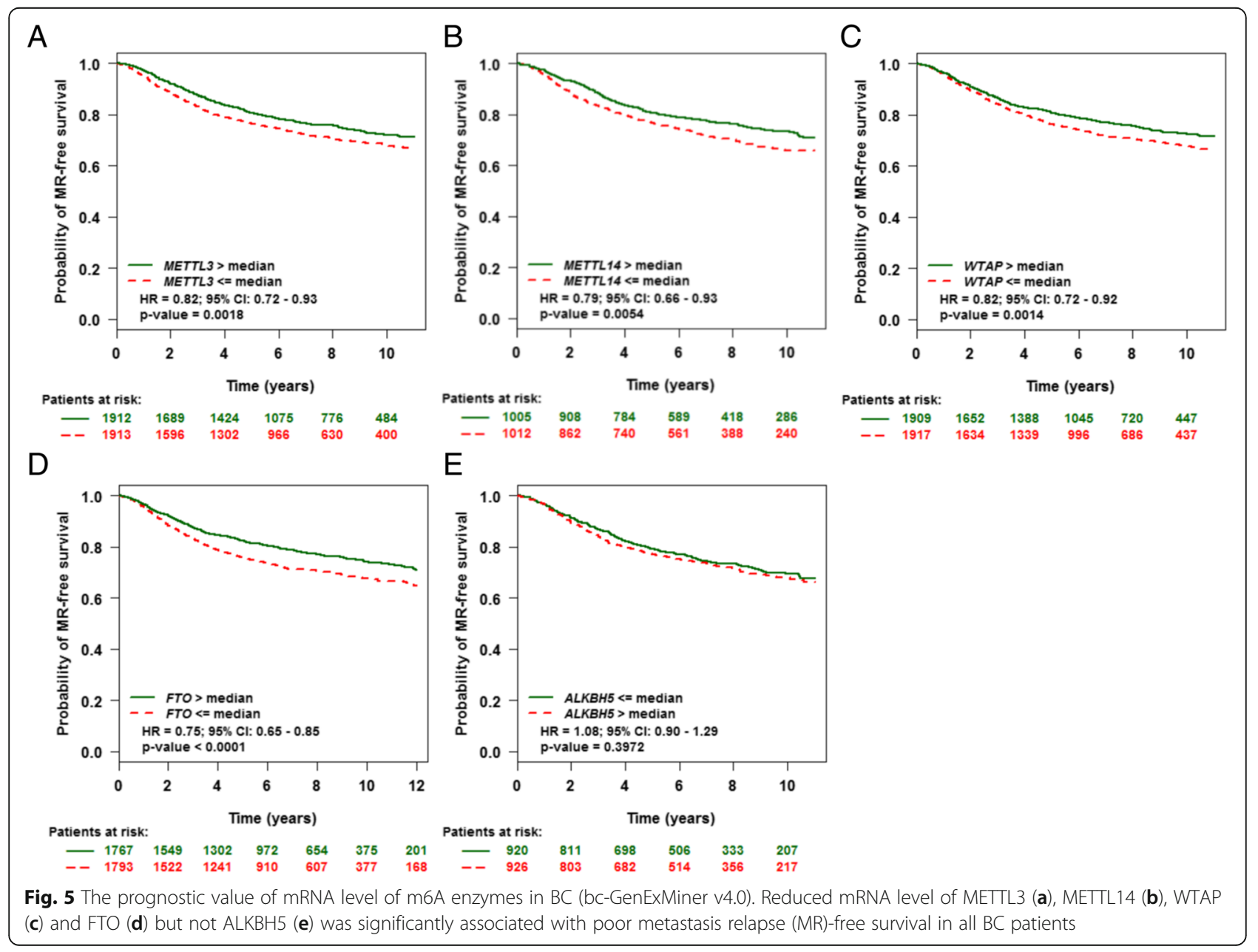


A

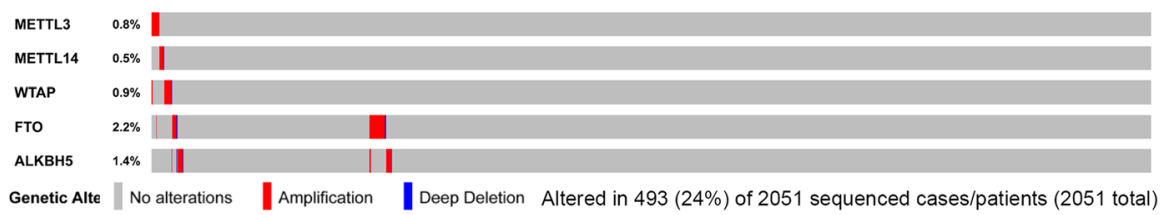

B

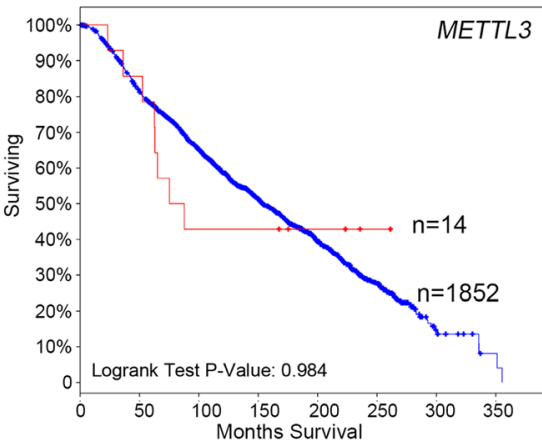

D

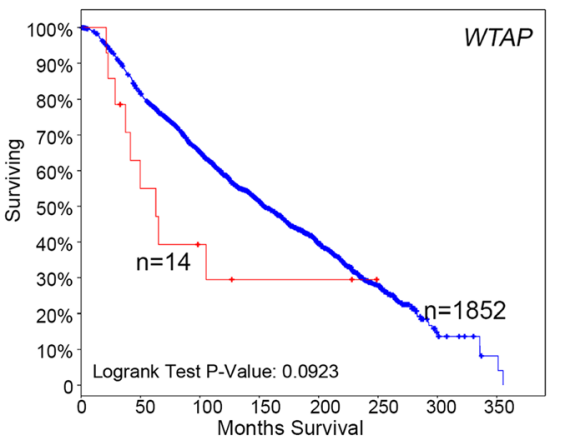

F

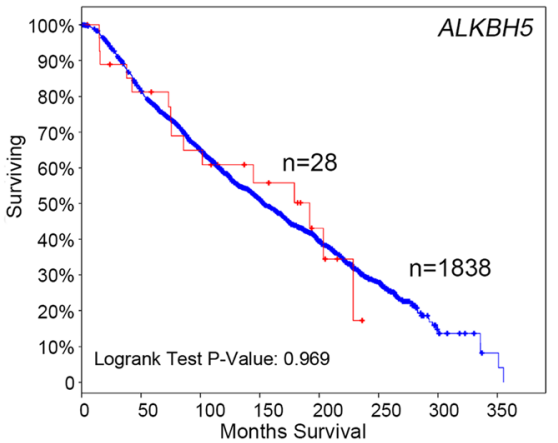

C

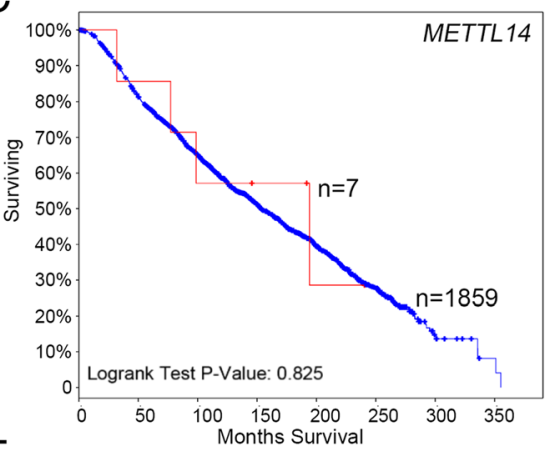

E

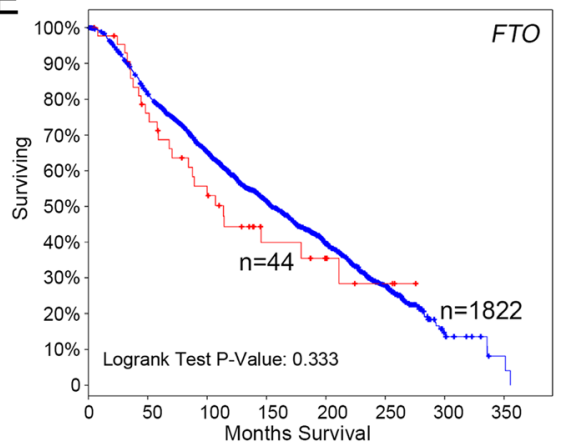

Cases with Alteration(s) in Query Gene(s)

Cases without Alteration(s) in Query Gene(s)

Fig. 6 Genetic alteration in m6A enzymes and association with prognosis in breast-invasive carcinoma from cBioPortal data analysis. a Oncoprint in cBioPortal was used to represent the proportion and distribution of samples with genetically altered m6A enyzmes in the METABRIC database. b-f Kaplan-Meier plots comparing overall survival with and without m6A enzyme alterations

instance, METTL3 is reported as an oncogene for lung adenocarcinoma, glioblastoma and hepatocellular carcinoma [36], whereas we found decreased METTL3 expression in $\mathrm{BC}$. A reasonable explanation for this paradox could be the differences in $\mathrm{m} 6 \mathrm{~A}$ modification status in various tumors as well as cancer heterogeneity, highlighting the differences in m6 A target gene repertoires among cancer cells.

In $\mathrm{BC}$ tissues, collaboration between RNA m6A member expression and distribution is close. The expression of the methylases METTL3 and METTL14 was positively correlated and high in normal breast-like and luminal A- and B-type BC. A reverse effect was found with demethylases. Furthermore, methylase activity was negatively related to that of demethylases, such as METTL3 versus ALKBH5. Thus, the exact expression and distribution might be necessary to detect the difference in clinicopathological and molecular subtypes of BC. As well, reduced level of the m6A members METTL3, METTL14, WTAP and FTO but not their 
mutation and overexpression was tightly associated with cancer progression and poor survival, and these could be developed as novel prognostic markers to predict tumor recurrence. Thus, m6A introduction (methylation) and m6A removal (demethylation) may be associated with the malignant phenotype of $\mathrm{BC}$ and a promising therapeutic target for clinical $\mathrm{BC}$. Uncovering the crucial functions of m6A patterns in RNA may lead to new treatment ideas for glioblastoma.

\section{Conclusions}

Our study indicated that abnormal mRNA expression but not gene mutation or amplification of m6A enzymes, especially METTL3, METTL14, WTAP and FTO, might be a novel diagnostic and prognostic strategy for $\mathrm{BC}$ and contribute to $\mathrm{BC}$ development. Determining whether the $\mathrm{m} 6 \mathrm{~A}$ target gene and pathway in the tumorigenesis of $\mathrm{BC}$ and the molecular mechanism is challenging but would be rewarding for illustration in vitro and in vivo. The present study opens a new era for epi-transcriptome research in $\mathrm{BC}$ based on m6A function and modification.

\section{Additional file}

\begin{abstract}
Additional file 1: Figure S1. Forest plot of mRNA expression of m6A enzymes for metastasis relapse (MR)-free survival in all BC patients by meta-analysis according to the bc-GenExMiner v4.0 database. Figure S2. The prognostic value of mRNA level of m6A enzymes in BC patients (RFS in Kaplan-Meier plotter). Table S1. List of primers used in QRT-PCR assays. Table S2. Univariate Cox analysis of METTL3 for clinical survival of breast cancer patients (data from bc-GenExMiner v4.0). Table S3. Univariate Cox analysis of METTL14 for clinical survival of breast cancer patients (data from bc-GenExMiner v4.0). Table S4. Univariate Cox analysis of WTAP for clinical survival of breast cancer patients (data from bc-GenExMiner v4.0). Table S5. Univariate Cox analysis of FTO for clinical survival of breast cancer patients (data from bc-GenExMiner v4.0). Table S6. Univariate Cox analysis of ALKBH5 for clinical survival of breast cancer patients (data from bc-GenExMiner v4.0). Table S7. Univariate Cox analysis of the prognostic value of METTL3 in breast cancer by clinicopathological factors. Table S8. Univariate Cox analysis of the prognostic value of METTL14 in breast cancer by clinicopathological factors. Table S9. Univariate Cox analysis of the prognostic value of WTAP in breast cancer by clinicopathological factors. Table S10. Univariate Cox analysis of the prognostic value of FTO in breast cancer by clinicopathological factors. Table S11. Univariate Cox analysis of the prognostic value of ALKBH5 in breast cancer by clinicopathological factors. (DOCX $601 \mathrm{~kb})$
\end{abstract}

\section{Abbreviations \\ ALKBH5: AlkB family member 5; BC: Breast cancer; FTO: Fat-mass- and obesity-associated protein; m6A: N6-methyladenosine; \\ METTL14: Methyltransferase-like 14; METTL3: Methyltransferase-like 3; WTAP: Wilms tumor 1-associated protein}

\section{Acknowledgements}

We acknowledge Laura Smales (BioMedEditing, Toronto, Canada) for English language editing.

\section{Funding}

The study was funded by The National Natural Science Foundation of China (No. 81200224). The funding body did not contribute to any of the following: design of the study, data collection, data analysis, interpretation of data, writing the manuscript or decision to publish.

\section{Availability of data and materials}

The datasets used and/or analyzed during the current study are presented within the manuscript and/or additional supporting files.

\section{Authors' contributions}

Conception and design: DH Z, LP W. Development of methodology: DH Z, LP W, DY W, and JF N. Acquisition, analysis and interpretation of data (e.g., statistical analysis, biostatistics, computational analysis): W L, LP W, DY W, DH $Z$ and JF N. Writing, review, and/or revision of the manuscript: DH Z, LP W. All authors read and approved the final manuscript.

\section{Ethics approval and consent to participate}

The use of clinical samples in our study was according to the Declaration of Helsinki and was approved by the Ethics Committee of the Second Affiliated Hospital of Wenzhou Medical University in Sept. 2017 (Number:L-2017-05).

Written informed consent was obtained from each participant.

\section{Consent for publication}

Not applicable

\section{Competing interests}

The authors declare that they have no competing interests.

\section{Publisher's Note}

Springer Nature remains neutral with regard to jurisdictional claims in published maps and institutional affiliations.

\section{Author details}

'Department of Cardiology, The Second Affiliated Hospital of Wenzhou Medical University, 109 Xueyuan Road, Wenzhou 325027, Zhejiang, China. ${ }^{2}$ The Thoracic Department of Harbin Medical University Cancer Hospital, 150 Haping Road, Harbin 150040, China. ${ }^{3}$ The Fourth Department of Medical Oncology, Harbin Medical University Cancer Hospital, 150 Haping Road, Harbin 150040, China. ${ }^{4}$ Center for Molecular and Translational Medicine, Georgia State University, 157 Decatur Street SE, Atlanta, GA 30303, USA.

Received: 7 May 2018 Accepted: 28 March 2019

Published online: 05 April 2019

\section{References}

1. Jaffrey SR, Kharas MG. Emerging links between $m(6)$ a and misregulated mRNA methylation in cancer. Genome Med. 2017;9(1):2.

2. Liu J, Yue Y, Han D, Wang X, Fu Y, Zhang L, Jia G, Yu M, Lu Z, Deng X, et al. A METTL3-METTL14 complex mediates mammalian nuclear RNA N6adenosine methylation. Nat Chem Biol. 2014;10(2):93-5.

3. Ping XL, Sun BF, Wang L, Xiao W, Yang X, Wang WJ, Adhikari S, Shi Y, Lv Y, Chen YS, et al. Mammalian WTAP is a regulatory subunit of the RNA N6methyladenosine methyltransferase. Cell Res. 2014;24(2):177-89.

4. Zheng G, Dahl JA, Niu Y, Fedorcsak P, Huang CM, Li CJ, Vagbo CB, Shi Y, Wang WL, Song SH, et al. ALKBH5 is a mammalian RNA demethylase that impacts RNA metabolism and mouse fertility. Mol Cell. 2013:49(1):18-29.

5. Barbieri I, Tzelepis K, Pandolfini L, Shi J, Millan-Zambrano G, Robson SC, Aspris D, Migliori V, Bannister AJ, Han N, et al. Promoter-bound METTL3 maintains myeloid leukaemia by m(6) A-dependent translation control. Nature. 2017:552(7683):126-31.

6. Geula S, Moshitch-Moshkovitz S, Dominissini D, Mansour AA, Kol N, Salmon-Divon M, Hershkovitz V, Peer E, Mor N, Manor YS, et al. Stem cells. m6A mRNA methylation facilitates resolution of naive pluripotency toward differentiation. Science. 2015;347(6225):1002-6.

7. Fustin JM, Doi M, Yamaguchi Y, Hida H, Nishimura S, Yoshida M, Isagawa T, Morioka MS, Kakeya H, Manabe I, et al. RNA-methylationdependent RNA processing controls the speed of the circadian clock. Cell. 2013;155(4):793-806.

8. Klungland A, Dahl JA. Dynamic RNA modifications in disease. Curr Opin Genet Dev. 2014;26:47-52.

9. Chen $M$, Wei $L$, Law $C T$, Tsang FH, Shen J, Cheng $C L$, Tsang LH, Ho DW, Chiu DK, Lee JM, et al. RNA N6-methyladenosine methyltransferase 
METTL3 promotes liver cancer progression through YTHDF2 dependent post-transcriptional silencing of SOCS2. Hepatology. 2017;67(6):2254-70.

10. Vu LP, Pickering BF, Cheng Y, Zaccara S, Nguyen D, Minuesa G, Chou T, Chow A, Saletore Y, MacKay M, et al. The N (6)-methyladenosine (m(6) a)forming enzyme METTL3 controls myeloid differentiation of normal hematopoietic and leukemia cells. Nat Med. 2017;23(11):1369-76.

11. Cui $Q$, Shi H, Ye P, Li L, Qu Q, Sun G, Sun G, Lu Z, Huang Y, Yang CG, et al. $M(6)$ a RNA methylation regulates the self-renewal and tumorigenesis of glioblastoma stem cells. Cell Rep. 2017;18(11):2622-34.

12. Li X, Tang J, Huang W, Wang F, Li P, Qin C, Qin Z, Zou Q, Wei J, Hua L, et al. The M6A methyltransferase METTL3: acting as a tumor suppressor in renal cell carcinoma. Oncotarget. 2017;8(56):96103-16.

13. Ma JZ, Yang F, Zhou CC, Liu F, Yuan JH, Wang F, Wang TT, Xu QG, Zhou WP, Sun SH. METTL14 suppresses the metastatic potential of hepatocellular carcinoma by modulating $\mathrm{N}(6)$-methyladenosine-dependent primary MicroRNA processing. Hepatology. 2017;65(2):529-43.

14. Bansal H, Yihua Q, lyer SP, Ganapathy S, Proia DA, Penalva LO, Uren PJ, Suresh U, Carew JS, Karnad AB, et al. WTAP is a novel oncogenic protein in acute myeloid leukemia. Leukemia. 2014;28(5):1171-4.

15. Xi Z, Xue Y, Zheng J, Liu X, Ma J, Liu Y. WTAP expression predicts poor prognosis in malignant glioma patients. Journal of molecular neuroscience : MN. 2016;60(2):131-6.

16. Li Z, Weng H, Su R, Weng X, Zuo Z, Li C, Huang H, Nachtergaele S, Dong L, $\mathrm{Hu} C$, et al. FTO plays an oncogenic role in acute myeloid leukemia as a $\mathrm{N}$ (6)-Methyladenosine RNA demethylase. Cancer Cell. 2017;31(1):127-41.

17. Su R, Dong L, Li C, Nachtergaele S, Wunderlich M, Qing Y, Deng X, Wang Y, Weng $\mathrm{X}$, Hu C, et al. R-2HG exhibits anti-tumor activity by targeting FTO/ m(6) a/MYC/CEBPA signaling. Cell. 2017;172(1-2):90-105.

18. Zhang C, Samanta D, Lu H, Bullen JW, Zhang H, Chen I, He X, Semenza GL. Hypoxia induces the breast cancer stem cell phenotype by HIF-dependent and ALKBH5-mediated m(6) A-demethylation of NANOG MRNA. Proc Natl Acad Sci U S A. 2016;113(14):E2047-56.

19. Okumura M, Ohta M, Tateyama H, Nakagawa K, Matsumura A, Maeda H, Tada H, Eimoto T, Matsuda H, Masaoka A. The World Health Organization histologic classification system reflects the oncologic behavior of thymoma: a clinical study of 273 patients. Cancer. 2002;94(3):624-32.

20. Rhodes DR, Kalyana-Sundaram S, Mahavisno V, Varambally R, Yu J, Briggs BB, Barrette TR, Anstet MJ, Kincead-Beal C, Kulkarni P, et al. Oncomine 3.0: genes, pathways, and networks in a collection of 18,000 cancer gene expression profiles. Neoplasia. 2007;9(2):166-80.

21. Gyorffy B, Lanczky A, Eklund AC, Denkert C, Budczies J, Li Q, Szallasi Z. An online survival analysis tool to rapidly assess the effect of 22,277 genes on breast cancer prognosis using microarray data of 1,809 patients. Breast Cancer Res Treat. 2010;123(3):725-31.

22. Jezequel P, Campone M, Gouraud W, Guerin-Charbonnel C, Leux C, Ricolleau G, Campion L. Bc-GenExMiner: an easy-to-use online platform for gene prognostic analyses in breast cancer. Breast Cancer Res Treat. 2012;131(3):765-75.

23. Pereira B, Chin SF, Rueda OM, Vollan HK, Provenzano E, Bardwell HA, Pugh M, Jones L, Russell R, Sammut SJ, et al. The somatic mutation profiles of 2,433 breast cancers refines their genomic and transcriptomic landscapes. Nat Commun. 2016;7:11479.

24. Curtis C, Shah SP, Chin SF, Turashvili G, Rueda OM, Dunning MJ, Speed D, Lynch AG, Samarajiwa S, Yuan Y, et al. The genomic and transcriptomic architecture of 2,000 breast tumours reveals novel subgroups. Nature. 2012; 486(7403):346-52.

25. Cerami E, Gao J, Dogrusoz U, Gross BE, Sumer SO, Aksoy BA, Jacobsen A, Byrne CJ, Heuer ML, Larsson E, et al. The cBio cancer genomics portal: an open platform for exploring multidimensional cancer genomics data. Cancer discovery. 2012;2(5):401-4.

26. Wei X, Zhang D, Dou X, Niu N, Huang W, Bai J, Zhang G. Elevated 14,15epoxyeicosatrienoic acid by increasing of cytochrome P450 2C8, 2C9 and $2 \mathrm{~J} 2$ and decreasing of soluble epoxide hydrolase associated with aggressiveness of human breast cancer. BMC Cancer. 2014;14:841.

27. Zhang D, Wu B, Wang P, Wang Y, Lu P, Nechiporuk T, Floss T, Greally JM, Zheng $D$, Zhou B. Non-CpG methylation by DNMT3B facilitates REST binding and gene silencing in developing mouse hearts. Nucleic Acids Res. 2017:45(6):3102-15.

28. Zhang DH, Wen XM, Zhang L, Cui W. DNA methylation of human telomerase reverse transcriptase associated with leukocyte telomere length shortening in hyperhomocysteinemia-type hypertension in humans and in a rat model. Circulation journal : official journal of the Japanese Circulation Society. 2014;78(8):1915-23.

29. Ma XJ, Dahiya S, Richardson E, Erlander M, Sgroi DC. Gene expression profiling of the tumor microenvironment during breast cancer progression. Breast cancer research : BCR. 2009;11(1):R7.

30. Richardson AL, Wang ZC, De Nicolo A, Lu X, Brown M, Miron A, Liao X, Iglehart JD, Livingston DM, Ganesan S. X chromosomal abnormalities in basal-like human breast cancer. Cancer Cell. 2006;9(2):121-32.

31. Turashvili G, Bouchal J, Baumforth K, Wei W, Dziechciarkova M, Ehrmann J, Klein J, Fridman E, Skarda J, Srovnal J, et al. Novel markers for differentiation of lobular and ductal invasive breast carcinomas by laser microdissection and microarray analysis. BMC Cancer. 2007;7:55.

32. Gluck S, Ross JS, Royce M, McKenna EF Jr, Perou CM, Avisar E, Wu L. TP53 genomics predict higher clinical and pathologic tumor response in operable early-stage breast cancer treated with docetaxel-capecitabine +/trastuzumab. Breast Cancer Res Treat. 2012;132(3):781-91.

33. Finak $G$, Bertos $N$, Pepin $F$, Sadekova $S$, Souleimanova M, Zhao H, Chen $H$, Omeroglu G, Meterissian S, Omeroglu A, et al. Stromal gene expression predicts clinical outcome in breast cancer. Nat Med. 2008;14(5):518-27.

34. Zhang S, Zhao BS, Zhou A, Lin K, Zheng S, Lu Z, Chen Y, Sulman EP, Xie K, Bogler O, et al. M(6) a demethylase ALKBH5 maintains Tumorigenicity of glioblastoma stem-like cells by sustaining FOXM1 expression and cell proliferation program. Cancer Cell. 2017;31(4):591-606 e596.

35. Fidler MM, Gupta S, Soerjomataram I, Ferlay J, Steliarova-Foucher E, Bray F. Cancer incidence and mortality among young adults aged 20-39 years worldwide in 2012: a population-based study. The Lancet Oncology. 2017; 18(12):1579-89.

36. Wang S, Sun C, Li J, Zhang E, Ma Z, Xu W, Li H, Qiu M, Xu Y, Xia W, et al. Roles of RNA methylation by means of $N(6)$-methyladenosine $(m(6)$ a) in human cancers. Cancer Lett. 2017:408:112-20.

37. Zhang C, Zhi WI, Lu H, Samanta D, Chen I, Gabrielson E, Semenza GL. Hypoxia-inducible factors regulate pluripotency factor expression by ZNF217- and ALKBH5-mediated modulation of RNA methylation in breast cancer cells. Oncotarget. 2016;7(40):64527-42.

38. Fry NJ, Law BA, Ilkayeva OR, Carraway KR, Holley CL, Mansfield KD. N (6)methyladenosine contributes to cellular phenotype in a genetically-defined model of breast cancer progression. Oncotarget. 2018;9(58):31231-43.
Ready to submit your research? Choose BMC and benefit from:
- fast, convenient online submission
- thorough peer review by experienced researchers in your field
- rapid publication on acceptance
- support for research data, including large and complex data types
- gold Open Access which fosters wider collaboration and increased citations
- maximum visibility for your research: over $100 \mathrm{M}$ website views per year
At BMC, research is always in progress.
Learn more biomedcentral.com/submissions 